\title{
An Analysis of Regional Inequalities in Per Capita Production and Causative Factors: Current Status of Agriculture, Manufacturing and Retail Trades in Vietnam ${ }^{\dagger}$
}

\author{
Yoji Kunimitsu*
}

\begin{abstract}
This paper examines the issue of regional inequalities in per capita production in Vietnam. In the 1990s, estimates indicate such inequalities may have widened, or at the very least persisted. It is concluded that regional inequalities have resulted from industrialization, restriction of internal migration, and the concentration of foreign direct investment and public investment in specific areas.
\end{abstract}

\section{Introduction}

Kuznets [11], in referring to his famous inverse-U hypothesis, argues that per capita income has diverged in parallel with economic growth in developing countries, and that regional inequalities in per capita income begin to converge only after a certain economic standards has been attained. Despite the difficulty of confirming this theory using chronological data for one country alone, we can nevertheless demonstrate an inverse-U curve by plotting the cross-sectional data for different countries in the graph with per capita GDP on the $\mathrm{x}$-axis and the Gini coefficient on the $\mathrm{y}$-axis (Paukert [13]). The inverse- $\mathrm{U}$ hypothesis has also been used to analyze regional inequalities among counties in the United States (Williamson [15]).

In a study concerning regional inequalities, Barro and Sala-i-Martin [2] defined $\beta$ convergence and $\sigma$ convergence, with $\beta$ convergence indicating the process by which less developed economies grow faster than developed ones. However, in the $\beta$ convergence process, it appears quite likely that there are more than two stable points. It may be that some groups will advanced toward and pass the higher point. To evaluate these effects, previous study has considered the $\sigma$ convergence process, by which the variance in per capita income or production converges to unity over time.

Since the 1970s, Asian NIEs and ASEAN countries achieved remarkable economic growth, the so-called "Asian miracle." This rapid economic growth has come widening income inequalities between rich and poor, or between city and rural dwellers. These countries could be described as experiencing the first half of inverse- $U$ curve.

What factors have led to Vietnamese high economic growth since the 1990s? This paper is intended to describe the chronological changes in regional inequalities and causative factors in Vietnam $^{1}$ in the $1990 \mathrm{~s}$, using the data of per capita production in agriculture, manufacturing (with this category including manufacturing industries, mining, electricity, and gas and water supply) and retail trades, as well as total figures for these categories.

+ This is a revised edition of a paper presented at the $37^{\text {th }}$ Annual Meeting of the Japan Section of the RSAI, Tohoku Gakuin University, November 2000. I wish to express my gratitude to the official discussants, Y. Ouchida, Kitakyushyu National College of Technology, L.Y. Kiminami, Ryukoku University, and anonymous referees for their comments.

* National Institute for Rural Engineering

${ }^{1}$ Kunimitsu [9] [10] provides the results of chronological influence or linkage among macro economic 


\section{Analysis Framework}

\subsection{Economic Outline}

Vietnam joined the ASEAN in 1995, since which time its GDP growth rate has been about $8 \%$ per year. The first, second, and tertiary industries all appear to have had an equal hand in contributing production shares toward the GDP in 1998. The growth rate in manufacturing is the highest of all the industries.

This acceleration in growth was backed by an economic structural reform popularly called "Doi-moi," which consists of policies such as free purchase rights for farm products, reforms of state enterprises through the introduction of market mechanisms, adjustment of foreign exchange rates, and the introduction of overseas capital. In particular, Vietnamese foreign policies are said to have been helpful in boosting economic growth. As shown in Table 1, we see that the growth rate of Vietnamese exports (US\$ base) far exceeds GDP. Despite high economic growth rates, the growth rate of population has been under $2 \%$ per year during the past 10 years.

In 1997, Vietnamese economic growth declined due to the Asian economic crisis, which began in Thailand and spread to Vietnam. However, its impact on Vietnam was small, compared to other ASEAN countries. One reason for the relatively moderate damage is that the Vietnamese economic scale was too small to form a tight linkage to foreign countries. A second factor is its less developed monetary market, which fortuitously prevented the rapid diffusion of capital across the country (see Aramaki [1]).

In examining the regional growth rates for production and population in Table 2, we can see that the manufacturing sphere has expanded faster than agriculture, and that the increasing rates of production are different in regions. On the other hand, small differences in regional growth rates for agricultural production is shown in this table.

Table 1 Economic Overview for Vietnam

\begin{tabular}{l|r|r|r}
\hline \multirow{2}{*}{} & \multicolumn{2}{|c|}{1998 (at 1994 price) } & $1995-98$ \\
\cline { 2 - 4 } & Bill.dong & Structure & G.R. (\%) \\
\hline GDP & 244,676 & $100 \%$ & 8.4 \\
Agriculture and Forestry & 52,099 & $21 \%$ & 4.4 \\
Fishing & 5,768 & $2 \%$ & 3.2 \\
Manufacturing & 63,315 & $26 \%$ & 14.7 \\
Construction & 18,674 & $8 \%$ & 9.3 \\
Retail Trades \& Repair & 41,170 & $17 \%$ & 7.5 \\
Others & 63,650 & $26 \%$ & 7.4 \\
\hline Gross Capital Formation & 70,714 & $29 \%$ & 10.9 \\
Final Consumption & 192,058 & $78 \%$ & 7.0 \\
Export (US\$) & 9,356 & - & 23.9 \\
Import (US\$) & 11,390 & - & 13.2 \\
\hline
\end{tabular}

Data: "Statistical Yearbook" Statistical Publishing

House, Hanoi

Note: Manufacturing include manufacturing industries, mining, electricity, and gas and water supply

variables by building econometric models and using a growth accounting approach. This paper focuses on cross-sectional inequalities in per capita production by province. 
Table 2 Growth Rate of production by Regions

$(\%)$

\begin{tabular}{l|r|r|r|r|r|r}
\hline \multirow{2}{*}{ Region } & \multicolumn{2}{|c|}{ Agriculture } & \multicolumn{2}{c|}{ Manufacturing } & \multicolumn{2}{c}{ Retail Trades } \\
\cline { 2 - 7 } & $1991-95$ & $1995-97$ & $1991-95$ & $1995-97$ & $1991-92$ & $1995-97$ \\
\hline North Mountain and Midland & 6.5 & 5.3 & 14.8 & 15.4 & -33.5 & 15.8 \\
Red River Delta & 11.5 & 4.1 & 19.1 & 14.5 & -30.0 & 7.6 \\
North Central Coast & 5.7 & 2.9 & 6.4 & 9.0 & -26.2 & 9.3 \\
South Central Coast & 0.0 & 2.7 & 6.3 & 13.4 & -18.9 & 7.7 \\
Central Highlands & 2.4 & 8.3 & 18.6 & 7.9 & 6.9 & 8.5 \\
North East South & 6.9 & 1.0 & 15.0 & 14.1 & 22.6 & 7.1 \\
Mekong River Delta & 5.6 & 5.8 & 5.6 & 8.2 & -21.0 & 8.3 \\
\hline
\end{tabular}

Data: "Statistical Yearbook" Statistical Publishing House, Hanoi

"Statistical Yearbook of Labor-invalids Social Affairs" Statistical Publishing House, Hanoi

\subsection{The Analytical Models}

In this paper, we will discuss regional inequalities in per capita production (including intermediate input) in agriculture, manufacturing, and retail trades. Other industries are excluded and total added values are neglected for the following reasons: First, there are no statistics for the provincial GDP, although GDP appears to be proportional to gross output. Second, the three industries examined here are all major industries, representing Vietnamese first, second, and tertiary industries. They hold the biggest production shares in their respective fields of economic activity. Third, in empirical studies on economic growth, many researchers are interested in issues related to the transition of the economy from agriculture to manufacturing or service sector (Hayami [5]).

In order to study $\beta$ convergence by each industry, following model is used (see Barro and Sala$\mathrm{i}-\operatorname{Martin}[2])^{2}$.

$$
\left(y_{k i, t}-y_{k i, o}\right)=(1-\pi)\left(y_{k i}^{*}-y_{k i, o}\right)=a+\beta y_{k i, o}
$$

where $k, i$ and $t$ are suffixes for industries, provinces and time, respectively. The variable $y$ shows per capita production or log converted per capita production (small letter variables stand for the value being divided by the population $N$ ). The $y^{*}$ is the ultimate per capita production with stable economic growth, and the $y_{0}$ is the initial per capita production. The $a, \beta$ and $\pi$ are parameters.

In cases where less developed regions are attempting to catch up to more developed areas the coefficient $\beta$ will be negative. When regional inequalities diverge, this coefficient will be positive. I assumed constant ultimate per capita production $\left(y^{*}\right)$, following Barro and Sala-i-Martin [2].

2 The closed economy neoclassical growth models predict that per capita growth rate tends to be inversely related to the starting level of output per person (see Koopman [9]). Per capita production in year $t$ is shown as

$$
d y_{t} / d t=b\left(y^{*}-y_{t}\right)
$$

Given that growth of $y_{t}$ declines monotonously toward the steady-state value, the average growth rate of $y$ over the interval between dates 0 and $T$ leads to

$$
\frac{\ln \left(y_{T}\right)-\ln \left(y_{0}\right)}{T}=\frac{\left(1-e^{-b T}\right)}{T}\left[\ln \left(y^{*}\right)-\ln \left(y_{0}\right)\right]
$$

as shown in equation (1) with log per capita production; $\ln \left(y_{t}\right)$.

If $d y_{t} / d t$ is constant, the average growth rate of $y$ is

$$
(1 / T) \cdot\left(y_{T}-y_{0}\right)=b^{\prime}(1 / T) \cdot\left(y^{*}-y_{0}\right)
$$

as shown in equation (1) with non-log per capita production; $y_{t}$. 
Because equation (1) is used for cross-sectional estimates, it is hard to determine based on the circumstances, whether each group within the overall economy converges into the same stable position. After taking this into consideration, we must use the following equation to examine $\sigma$ convergence (see Ben-David [3]) .

$$
\begin{gathered}
z_{t}=\Phi z_{t-1}+\sum_{j=1}^{k} e_{j} \Delta z_{t-j} \\
z_{t}=y_{t}-\bar{y}_{t}, \quad \text { or } \quad z_{t}=\ln \left(y_{t}\right)-\overline{\ln \left(y_{t}\right)} \\
\Delta z_{t}=z_{t}-z_{t-1}
\end{gathered}
$$

In these equations, barred variables imply the average of all provinces, and parameter $\Phi$ is the group's convergence coefficient. This $\Phi$ represents the average rate of convergence within the group when its value falls below unity. An outcome of $\Phi>1$ indicates regional divergence among the group members.

The second term is for removing the unit-root bias in dealing with time series data by augmented Dickey Fuller estimation. When there is pooling, as is the case here, Quah [14] finds it appropriate to examine the $t$-statistic as if it were normal asymptotically. This is corroborated by Levin and Lin [12], who show that the applicable critical $t$-values are nearly identical to the standard $\mathrm{t}$-value, in the absence of a drift or trend.

Following Campbell et al. [4], $k$ is chosen by the upper bound of $k_{\max }$ and used to examine the significant level of $e_{k}$. If the $t$-statistic is not significant at the $10 \%$ level, then $k$ is reduced by one and equation (2) is re-estimated, until all $e_{j}$ are significant at the $10 \%$ level, or $k$ is set to 0 and no $e_{k}$ occurs in equation (2).

\subsection{Causative Factors for Regional Economic Inequalities}

To clear causative factors for regional inequalities in per capita production, it is useful to take the standard regression analysis (so-called pass analysis). Before we move on to the regression model, we will begin our discussion by considering the background of the model.

First, Kuznets [11] and Williamson [15] said that matured labor and capital stock move to developed areas from less developed areas in the first stage of industrialization. This makes

${ }^{3}$ Ben-David [9] used log per capita production to derive equation (2). In this paper, we are interested in the movement of regional inequalities measured with both variance and coefficient of variation. The former means an absolute quantity of variation, and related to non-log model of equation (1). The latter means comparative change in regional inequalities, and is related to the $\log$ model of equation (1).

Using Taylor expansion with $\bar{y}, \ln (y)$ is

$$
\ln (y)=\overline{\ln (y)}+\frac{1}{\bar{y}}(y-\bar{y})+R_{n}
$$

where $R_{n}$ is the second term of approximation and will be neglected (see Kawabata [9]). The standard deviation of $\ln (y)$ is defined as follows.

$$
\operatorname{Var}^{1 / 2}[\ln (y)]=E\left[\frac{1}{\bar{y}}(y-\bar{y})^{2}\right]^{1 / 2}=\frac{\operatorname{Var}^{1 / 2}[y]}{E[y]}
$$

where "Var" means variance, and " $E$ " means expectation. The right hand of equation is the coefficient of variation of $y$.

The $\sigma_{\log }$ of Ben-David's model is defined as follows.

$$
\sigma_{\mathrm{log}}=\frac{\ln \left(y_{t}\right)-\overline{\ln \left(y_{t}\right)}}{\ln \left(y_{t-1}\right)-\overline{\ln \left(y_{t-1}\right)}}=\left[\frac{\overline{y_{t-1}}}{\overline{y_{t}}}\right] \frac{y_{t}-\overline{y_{t}}}{y_{t-1}-\overline{y_{t-1}}}=\left(\overline{y_{t-1}} / \overline{y_{t}}\right) \sigma_{\text {non }-10 \mathrm{~g}}
$$

Hence, we can say that in a developing economy $\left[\left(\overline{y_{t-1}} / \overline{y_{t}}\right)<1\right]$, a $\sigma$ convergence coefficient estimated from a log variable is smaller than from a non-log variable, and that a log model more readily shows convergence, compared to a non-log model. 
regional inequalities diverge in economic standard and living environment. As industrialization matures and becomes more widespread, regional inequalities tend to converge. To see this influence, I will calculate the regional correlation of variables per capita production y, population $\mathrm{N}$ and total production $\mathrm{Y}$, and their average growth rate in each group that will be classified in order to per capita production.

Second, according to "imbalanced growth," a theory of Hirschman's [6], the government would be able to make regional inequalities converge by investing public capital in less developed areas. In the case of economic growth under the leadership of private sectors, on the contrary, it becomes necessary for the government to invest public capital in developed areas, and to remove the bottleneck of growth. Anyway, in case of the influence of public investment or private investment, there may be positive impact to the regional production.

Added to these, it is quite likely that foreign direct investment under open market policy also improves the production, and educational system improves the quality of labor. Following equations can explain the above-mentioned factors against the change of production.

$$
\Delta y_{k}=\alpha_{1} \Delta k g+\alpha_{2} \Delta k p+\alpha_{3} \Delta k e+\alpha_{4} k f+\alpha_{5} \Delta a r
$$

$y_{k}$ : per capita gross production in each industry and their total amount

$\mathrm{kg}$ : per capita public capital stock invested by local government at the beginning of the year

$k p$ : per capita number of private enterprises at the beginning of the year, assumed to indicate private capital stock levels

$k e$ : per capita educational environment, represented by numbers of classrooms in secondary schools

$k f$ : per capita total foreign direct investment, represented by summation of registered foreign capital up to 1992 or 1997

ar: per capita cultivated area, (used only for agriculture)

Here, the ' $\Delta$ ' symbol represents a difference. The $k f$ indicates total foreign capital divided by provincial population, and at the same time it indicates a change in that capital. Since little foreign investment into domestic projects arrived before 1988, the changes in capital stock levels for 10 years can be represented by summation of investment.

In addition to equation (3), the production function will be estimated from cross-sectional data. The equation is

$$
Y T=f(N, K G, K P, K E, K F, A R)
$$

where each capital letter represents the total value of each variable.

Third, it is assumed that agricultural production $Y A$ is strongly affected by cultivated area. The growth rate of production will be divided into increase in land productivity and expansion of cultivated areas.

$$
\frac{d(Y A)}{Y A}=\frac{d(Y A / A R)}{(Y A / A R)}+\frac{d(A R)}{A R}
$$

where ' $d$ ' is the symbol of differential.

\subsection{Data for Analysis}

In this paper, regional data classified into 52 provinces was used to analyze regional conditions ${ }^{4}$. Data source of population is 'Statistical Yearbook of Labor-invalids Social Affairs' and that of other data is 'Statistical Yearbook'. These are both published by Statistical Publishing House in Hanoi

${ }^{4}$ Data classified into 53 provinces is found in the Statistical Yearbook up to 1996 . I used data for 52 provinces, excluding Ba-Ria Vung-Tau, which is characterized by unusual per capita production due to a concentration of foreign companies. Although regional data has been published for 59 
every year. The Statistical Yearbook provides gross output data for each industry, excluding agriculture before 1994, and excluding retail trades in 1993 and in 1994. For this reason, some compliment was necessary to estimate the lacunae in data.

In agriculture, from 1991 to 1994, gross output was calculated from total production (converted to rice) multiplied by the ratio derived from gross output (in fixed price) versus total production in 1995, after confirming that the ratio is stable from 1995 to 1998.

For retail trades, after calculating the gross output in fixed price by the GDP deflator for the "wholesale and retail trade," the line complement was used only for data in the second terms of equation (2). For other terms, the period analyzed had to be restricted to post-1995.

Public capital stock is represented by the sum of investment for five years, following the Perpetual Inventory Method. For example, capital stock in 1997 is calculated from the sum of investment from 1993 to 1997 . Increase in capital stock is calculated by subtracting capital stock in 1992 from that in 1997. In these operations, fixed price investment data was calculated by the deflator of public investment in the national account. There is provincial data for the local governments, but not for the central government. For this reason, analysis has to be restricted to the influence of public capital stock invested by local governments, in spite of that over half of all public projects were funded by the central government.

\section{Analysis Results}

\subsection{Regional Inequalities in per Capita Production}

Figure 1 is the chronological change in the coefficient of variation calculated from per capita production by industry. The figure shows that the coefficient of variation ranks in the following order : manufacturing $>$ retail trades $>$ total $>$ agriculture, with a tendency to increase except for retail trades.

Table 3 shows the results obtained from equation (1), for investigating whether regional inequalities converge according to $\beta$ convergence process. In this table, both $\mathrm{R}$ square and $\mathrm{F}$ statistics are low in log models, as an exception to the retail trades results. It is reasonable to suppose that the

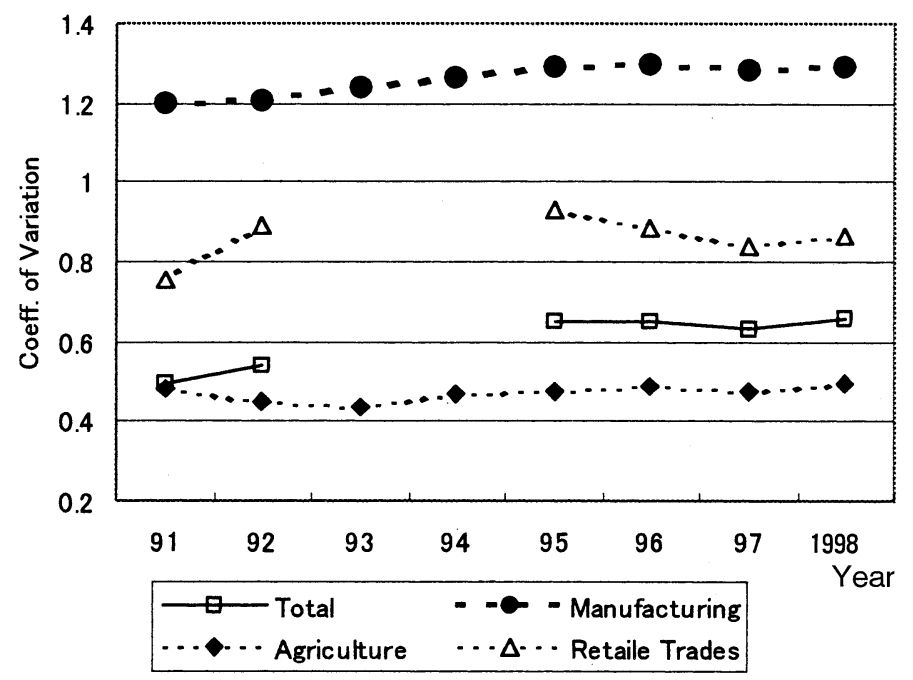

Fig. 1 Coefficients of Variation in Per-capita Production

classifications of provinces since 1997, I aggregated some provinces into 52 classifications in order to make chronological adjustments. 
Table 3 Estimated $\beta$ Convergence Coefficients by Industries

\begin{tabular}{|c|c|c|c|c|c|}
\hline & & $\begin{array}{c}\text { Total } \\
\text { Coeff. ( } t \text {-stat. })\end{array}$ & $\begin{array}{c}\text { Agriculture } \\
\text { Coeff. (t-stat.) }\end{array}$ & $\begin{array}{l}\text { Manufucturing } \\
\text { Coeff. ( } t \text {-stat.) }\end{array}$ & $\begin{array}{l}\text { Retail Trades } \\
\text { Coeff. ( } t \text {-stat.) }\end{array}$ \\
\hline $\begin{array}{l}\infty \\
0 \\
0 \\
1 \\
5 \\
0 \\
z \\
z \\
\Sigma\end{array}$ & $\begin{array}{l}\text { Constant } \\
\beta \quad\left[y_{0}\right] \\
R \text {-square } \\
F \text {-statistic }\end{array}$ & $\begin{array}{c}-15.18 \quad(-0.2) \\
0.210\left(8.7^{* *}\right) \\
0.60 \\
75.1^{* *}\end{array}$ & $\begin{array}{c}-34.45 \quad(-0.9) \\
0.146\left(4.6^{* *}\right) \\
0.30 \\
21.5^{* *}\end{array}$ & $\begin{array}{c}16.81 \quad(0.4) \\
0.352\left(10.5^{* *}\right) \\
0.69 \\
111.1^{* *}\end{array}$ & $\begin{array}{c}101.3 \quad\left(2.5^{* *}\right) \\
0.068\left(2.2^{* *}\right) \\
0.09 \\
4.9^{* *}\end{array}$ \\
\hline $\begin{array}{c}\overline{0} \\
\sum_{0}^{0} \\
\sum_{\infty}^{\infty} \\
0 \\
1\end{array}$ & $\begin{array}{l}\text { Constant } \\
\beta\left[\ln \left(y_{0}\right)\right] \\
R \text {-square } \\
F \text {-statistic }\end{array}$ & $\begin{array}{c}-0.03 \quad(-0.2) \\
0.027 \quad(1.2) \\
0.026 \\
1.3\end{array}$ & $\begin{array}{c}-0.11 \quad(-1.6) \\
0.050\left(2.2^{* *}\right) \\
0.087 \\
4.8^{* *}\end{array}$ & $\begin{array}{c}0.15\left(2.1^{* *}\right) \\
-0.009(-0.3) \\
0.002 \\
0.12\end{array}$ & $\begin{array}{c}0.42\left(3.3^{* *}\right) \\
-0.118\left(-2.7^{* *}\right) \\
0.12 \\
7.1^{* *}\end{array}$ \\
\hline
\end{tabular}

Note ; “**” ; $5 \%$ significant level of $t$-test, “*” ; $10 \%$ significant level of $t$-test.

conformity to actual data of the non-log model is higher than for the log model. The $\beta$ coefficient in manufacturing is the largest and suggests the highest divergence in the non-log model. Other industries show weak $\beta$ divergence.

Table 4 shows the results of equation (2) to examine the $\sigma$ convergence process. As for total production, the estimated $\Phi$ in two of three years exceeds unity in the non-log model, indicating $\sigma$ divergence. The $\log$ model shows continuation of regional inequalities, at least showing no convergence.

\subsection{The Contribution of Each Factor to Production}

\section{(1) Industrialization}

To see which industries have diverged in the 1990 s, we can examine the estimated results for the $\Phi$ coefficient by industries in Table 5. In five of the six years, estimated $\Phi$ coefficients exceed unity with greater than $90 \%$ probability, indicating divergence in manufacturing. The half of estimated $\Phi$ coefficients in agriculture exceed unity, indicating weak divergence. The results for retail trades suggest both divergence and convergence.

Table 6 shows the coefficients of correlation between three industries and the ratio of standard deviation in each industry to that of total production. The correlation between agriculture and other industries is low enough to be seen as zero, but the correlation between manufacturing and retail trades is high, showing similar regional patterns. The ratios of standard deviation in each industry show that most regional differences in total production are due to regional differences in

Table 4 Estimated $\sigma$ Convergence Coefficients in per Capita Total Production

\begin{tabular}{|c|c|c|c|c|c|c|}
\hline \multicolumn{2}{|c|}{ Year } & $\Phi$ & $\begin{array}{c}t \text {-statistic } \\
\left(H_{0}: \Phi=1\right)\end{array}$ & $k$ & $R^{2}$ & $F$-statistic \\
\hline 이 & 1998 & 1.071 & $5.65^{* *}$ & 0 & 0.993 & $7169 * *$ \\
\hline 둉 & 1997 & 0.991 & -0.62 & 2 & 0.996 & $4246^{* *}$ \\
\hline$z^{z}$ & 1996 & 1.073 & $5.27^{* *}$ & 1 & 0.994 & $4483^{* *}$ \\
\hline$\vec{\nabla}$ & 1998 & 1.020 & 1.28 & 0 & 0.988 & $4382^{* *}$ \\
\hline$\sum_{0}$ & 1997 & 0.996 & -0.33 & 0 & 0.993 & $6627^{* *}$ \\
\hline ( & 1996 & 1.010 & 0.80 & 0 & 0.992 & $6019^{* *}$ \\
\hline
\end{tabular}

Note ; “**”; $5 \%$ significant level of $t$-test, “*”; $10 \%$ significant level of $t$-test. 
Table 5 Estimated $\sigma$ Convergence Coefficients in Non-log Models by Industries

\begin{tabular}{c|c|c|c|c|c|c|c|c|c|c|c|c}
\hline \multirow{2}{*}{ Year } & \multicolumn{4}{|c|}{ Agriculture } & \multicolumn{4}{c|}{ Manufacturing } & \multicolumn{3}{c}{ Retail Trades } \\
\cline { 2 - 12 } & $\Phi$ & $\begin{array}{c}t \text {-statistic } \\
\left(H_{0}: \Phi=1\right)\end{array}$ & $k$ & $R^{2}$ & $\Phi$ & $\begin{array}{c}t \text {-statistic } \\
\left(H_{0}: \Phi=1\right)\end{array}$ & $k$ & $R^{2}$ & $\Phi$ & $\begin{array}{c}t \text {-statistic } \\
\left(H_{0}: \Phi=1\right)\end{array}$ & $k$ & $R^{2}$ \\
\hline 1998 & 1.058 & $3.61^{* *}$ & 1 & 0.989 & 1.049 & $3.66^{* *}$ & 1 & 0.998 & 1.025 & 1.22 & 1 & 0.981 \\
1997 & 0.995 & -0.23 & 3 & 0.990 & 0.980 & -0.84 & 3 & 0.997 & 0.976 & $-1.93^{*}$ & 0 & 0.992 \\
1996 & 1.070 & $4.44^{* *}$ & 0 & 0.989 & 1.083 & $10.70^{* *}$ & 1 & 0.998 & 1.057 & $3.15^{* *}$ & 0 & 0.985 \\
1995 & 1.011 & 0.44 & 0 & 0.971 & 1.096 & $2.14^{* *}$ & 0 & 0.922 & - & - & - & - \\
1994 & 1.081 & $2.00^{* *}$ & 2 & 0.936 & 1.116 & $5.00^{* *}$ & 0 & 0.978 & - & - & - & - \\
1993 & 0.958 & -0.97 & 0 & 0.906 & 1.120 & $8.01^{* *}$ & 0 & 0.991 & - & - & - & - \\
\hline
\end{tabular}

Note; “**”; $1 \%$ significant level of $t$-test, “*”; $5 \%$ significant level of $t$-test.

Table 6 Correlation Coefficients and Standard Deviation of Production by Industries

\begin{tabular}{l|c|c|c|c}
\hline & Total Prod. & Agriculture & Manufacturing & Retail Trades \\
\hline Correlation to Total Prod. & - & 0.168 & $0.988^{* *}$ & $0.984^{* *}$ \\
Standard Deviation (1998) & 10,534 & 1,239 & 5,885 & 4,605 \\
& $(1.00)$ & $(0.12)$ & $(0.56)$ & $(0.44)$ \\
\hline
\end{tabular}

Note; “**"; $5 \%$ significant level of $t$-test, “*”; $10 \%$ significant level of $t$-test.

manufacturing.

As mentioned above, regional inequalities diverge for agriculture and manufacturing. It appears quite likely that the regional inequalities cancel out between the two industries.

To see this more precisely, let us look at which area marks high or low increase in per capita production in Table 7. Industrialization is developing in Hochi Min City (North East South), Hanoi (Red River Delta), and in the outskirts of these provinces. Agriculture is currently prospering in the Mekong River Delta, despite the low increase in manufacturing there. North Mountain and Midland areas are less developed in total production.

Table 8 shows the estimated $\Phi$ by three groups of provinces. Each group is clustered according to per capita production and consists of 17 or 18 provinces. As the $\Phi$ coefficients indicate, a group in the middle range shows the continuity or weak convergence of regional inequalities. By contrast, over half of $\Phi$ coefficients in the higher group exceed unity during the periods analyzed, indicating divergence.

Table 7 High or Low Rank Provinces of Increase in per Capita Production by Industries

(Number of Provinces)

\begin{tabular}{l|c|c|c|c|c|c|c|c}
\hline \multirow{2}{*}{ Region } & \multicolumn{2}{|c|}{ Total Prod. } & \multicolumn{2}{c|}{ Agriculture } & \multicolumn{2}{c|}{ Manufacturing } & \multicolumn{2}{c}{ Retail Trades } \\
\cline { 2 - 8 } & Higher & Lower & Higher & Lower & Higher & Lower & Higher & Lower \\
\hline North Mountain and Midland & 1 & 3 & & & & 1 & 1 & 2 \\
Red River Delta & 1 & & & & 2 & & 1 & 3 \\
North Central Coast & & 1 & & 1 & & & & \\
South Central Coast & & 1 & & 2 & & & & \\
Central Highlands & 3 & & 2 & & & 1 & & \\
North East South & & & 2 & 3 & & 1 & \\
Mekong River Delta & & & 3 & & & 3 & 2 & \\
\hline
\end{tabular}


Table 8 Estimated $\sigma$ Convergence Coefficients of Non-log per Capita Production by Ranges

\begin{tabular}{|c|c|c|c|c|c|c|c|c|c|c|c|c|c|}
\hline & \multicolumn{4}{|c|}{ Higher Range; First 1/Last 17} & \multicolumn{4}{|c|}{ Middle Range ; First 18/Last 35} & \multicolumn{4}{|c|}{ Lower Range ; First 36/Last 52} \\
\hline & & \multirow{2}{*}{$\frac{\Phi}{1.091}$} & \multirow{2}{*}{$\begin{array}{c}t \text {-statistic } \\
\left(H_{0}: \Phi=1\right)\end{array}$} & \multirow{2}{*}{$\frac{k}{0}$} & \multirow{2}{*}{$\begin{array}{c}R^{2} \\
0.99\end{array}$} & \multirow{2}{*}{$\frac{\Phi}{0.966}$} & \multirow{2}{*}{$\begin{array}{c}t \text {-statistic } \\
\left(H_{0}: \Phi=1\right) \\
-0.34\end{array}$} & \multirow{2}{*}{$k$} & \multirow{2}{*}{$\frac{R^{2}}{0.85}$} & \multirow{2}{*}{$\frac{\Phi}{1.229}$} & $\begin{array}{l}t \text {-statistic } \\
\left(H_{0}: \Phi=1\right)\end{array}$ & $k$ & $R^{2}$ \\
\hline & 1998 & & & & & & & & & & $1.84^{* *}$ & 4 & 0.95 \\
\hline 0 & 1997 & 1.016 & 0.70 & 0 & 0.99 & 0.965 & -0.44 & 0 & 0.90 & 1.137 & $2.52^{* *}$ & 0 & 0.97 \\
\hline & 1996 & 1.071 & $2.63^{* *}$ & 0 & 0.99 & 1.056 & 1.18 & 0 & 0.97 & 1.136 & $1.44^{* *}$ & 0 & 0.90 \\
\hline \multirow{6}{*}{ 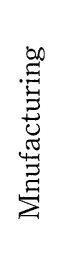 } & 1998 & 1.052 & $2.21^{* *}$ & 1 & 0.99 & 0.901 & -1.01 & 1 & 0.89 & 0.909 & -1.80 & 0 & 0.95 \\
\hline & 1997 & 0.957 & -1.14 & 1 & 0.99 & 0.960 & -0.57 & 1 & 0.94 & 1.074 & 1.47 & 1 & 0.97 \\
\hline & 1996 & 1.075 & $6.45^{* *}$ & 1 & 0.99 & 0.767 & $-1.76^{*}$ & 1 & 0.79 & 1.021 & 0.80 & 0 & 0.99 \\
\hline & 1995 & 1.028 & 0.32 & 0 & 0.90 & 0.430 & $-8.06^{* *}$ & 0 & 0.69 & 0.849 & -1.63 & 0 & 0.84 \\
\hline & 1994 & 1.126 & $3.07^{* *}$ & 0 & 0.98 & 0.707 & $-2.32 * *$ & 0 & 0.65 & 1.183 & 1.10 & 0 & 0.76 \\
\hline & 1993 & 1.123 & $4.13^{* *}$ & 0 & 0.99 & 1.071 & 0.96 & 1 & 0.96 & 0.899 & -1.35 & 1 & 0.92 \\
\hline
\end{tabular}

Note ; “**”; $5 \%$ significant level of $t$-test, “*” ; $10 \%$ significant level of $t$-test.

\section{(2) Internal Migration}

Table 9 shows how per capita production relates to population. The correlation between per capita production and population is weaker than the correlation between per capita production and total production. The average increase rate in each of the three groups, ranked by per capita production, shows the following. First, the increase rate of total production exceeds the rate of per capita production by far, and the rates in the higher and middle groups are greater than in the lower group. Second, the rate of increase in population in each group tends in the same direction, as for total production, but the tendency is less marked than for total production. This may be explained by population movements driven by economic growth, although such movements would be relatively minor. These relatively minor population shifts over time accentuated the regional inequalities evaluated with per capita production.

\section{(3) Capital Stock, Foreign Direct Investment, Education, and Cultivated Areas}

Table 10 and 11 were calculated through standard stepwise regression in equation (3) and (4). These results first show that higher levels of public investment or foreign direct investment correlated with faster rates of total per capita production growth.

Second, the inventory of cultivated areas also influences growth in total per capita production, through increased agricultural production. To show this more precisely, Table 12 is prepared for factor analysis. In southern regions-for example, in the Mekong Delta, where agricultural production is concentrated in Vietnam, the degree of contribution of cultivated areas exceeds $50 \%$.

Third, the educational environment does not affect total per capita production, since its effects within manufacturing and retail trade cancel out. Anyway, in regard to the Vietnamese educa-

Table 9 Influence of Total Production and Population on per Capita Production

\begin{tabular}{|c|c|c|c|c|}
\hline & & Total per Capita & Population & Total Production \\
\hline \multicolumn{2}{|c|}{$\begin{array}{l}\text { Correlation to Total per Capita Prod. } \\
\text { Ratio of Standard Deviation ('98/'95) }\end{array}$} & $\overline{-}$ & $\begin{array}{l}0.541^{* *} \\
1.07\end{array}$ & $\begin{array}{l}0.850^{* *} \\
1.32\end{array}$ \\
\hline 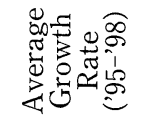 & $\begin{array}{l}\text { Higher Range } \\
\text { Middle Range } \\
\text { Lower Range }\end{array}$ & $\begin{array}{l}6.89 \\
6.87 \\
5.07\end{array}$ & $\begin{array}{l}1.92 \\
1.97 \\
1.60\end{array}$ & $\begin{array}{l}8.93 \\
8.95 \\
6.75\end{array}$ \\
\hline
\end{tabular}

Note; “**”; $5 \%$ significant level of $t$-test, “*”; $10 \%$ significant level of $t$-test. 
Table 10 Factors Related to the Change of per Capita Production $\left(\Delta y_{k}\right)$ from 1995 to 1998

(Stepwise Pass Analysis in equation (3))

\begin{tabular}{l|c|c|c|c}
\hline \multicolumn{1}{c|}{ Independent Variables } & $\begin{array}{c}\text { Total } \\
\text { Coeff. }(t \text {-stat. })\end{array}$ & $\begin{array}{c}\text { Agriculture } \\
\text { Coeff. }(t \text {-stat. })\end{array}$ & $\begin{array}{c}\text { Manufucturing } \\
\text { Coeff. }(t \text {-stat. })\end{array}$ & $\begin{array}{c}\text { Retail Trades } \\
\text { Coeff. }(t \text {-stat. })\end{array}$ \\
\hline$\Delta$ Public Capital Stock & $0.263\left(2.9^{* *}\right)$ & - & $0.123(1.4)$ & $0.462\left(3.5^{* *}\right)$ \\
$\Delta$ Private Enterprises & - & - & - & - \\
$\Delta$ Education (Classes) & - & - & $-0.128(-1.3)$ & $0.229\left(1.7^{*}\right)$ \\
Foreign Direct Investment & $0.721\left(7.7^{* *}\right)$ & - & $0.825\left(8.5^{* *}\right)$ & - \\
$\Delta$ Cultivated Area & $0.140(1.5)$ & $0.386\left(3.0^{* *}\right)$ & & \\
\hline$R$-square (Addjusted) & 0.57 & 0.13 & 0.61 & 0.18 \\
$F$-statistic & $23.4^{* *}$ & $8.8^{* *}$ & $28.1^{* *}$ & $6.7^{* *}$ \\
\hline
\end{tabular}

Note ; “**”; $5 \%$ significant level of $t$-test, "*”; $10 \%$ significant level of $t$-test.

Table 11 Factors Related to the Total Production (YT) in 1998

(Stepwise pass analysis in Equation (4))

\begin{tabular}{l|c|c}
\hline \multicolumn{1}{c|}{ Independent Variable } & $\begin{array}{c}\text { Non-log Model } \\
\text { Coeff. }(t \text {-stat. }\end{array}$ & $\begin{array}{c}\text { Log Model } \\
\text { Coeff. }(t \text {-stat.) }\end{array}$ \\
\hline Public Capital Stock & $0.612\left(20.2^{* *}\right)$ & $0.328\left(3.7^{* *}\right)$ \\
Private Enterprises & - & - \\
Education (Classes) & - & $0.201(1.3)$ \\
Foreign Direct Investment & $0.390\left(12.9^{* *}\right)$ & $0.176\left(2.1^{* *}\right)$ \\
Popuration & $0.064\left(2.2^{* *}\right)$ & $0.256(1.1)$ \\
Cultivated Area & $0.129\left(5.7^{* *}\right)$ & $0.170\left(1.7^{*}\right)$ \\
\hline$R$-square (Addjusted) & 0.985 & 0.831 \\
$F$-statistic & $831.0^{* *}$ & $51.1^{* *}$ \\
\hline
\end{tabular}

Note; “**” ; $5 \%$ significant level of $t$-test, “*”; $10 \%$ significant level of $t$-test.

Table 12 Degree of Contribution of Cultivated Area and Land Productivity in Agriculture (1991-98)

(\%)

\begin{tabular}{|c|c|c|c|}
\hline \multirow[b]{2}{*}{ Region } & \multirow{2}{*}{$\begin{array}{l}\text { Growth Rate } \\
\text { of Agri. Prod. }\end{array}$} & \multicolumn{2}{|c|}{ Degree of Contribution } \\
\hline & & $\begin{array}{c}\text { Cultivated } \\
\text { Area }\end{array}$ & $\begin{array}{c}\text { Land } \\
\text { Productivity }\end{array}$ \\
\hline North Mountain and Midland & 5.74 & 28.7 & 71.3 \\
\hline Red River Delta & 8.33 & -11.7 & 111.7 \\
\hline North Central Coast & $\cdot 4.94$ & -1.2 & 101.2 \\
\hline South Central Coast & 1.84 & 14.6 & 85.4 \\
\hline Central Highlands & 7.16 & 13.2 & 86.8 \\
\hline North East South & 5.78 & 56.9 & 43.1 \\
\hline Mekong River Delta & 5.61 & 76.6 & 23.4 \\
\hline Total & 5.47 & 37.7 & 62.3 \\
\hline
\end{tabular}

tional system, despite some technical problems, it appears that educational levels are already quite high and equal throughout the country under the socialist system, leaving little room for affecting regional inequalities. 
Fourth, the number of private enterprises does not have a strong effect on any of the industries discussed here. The variable used here may be unsuitable for examining private capital stock. The quality of the company is likely to be a more significant factor in relation to differences in production than the quantity.

Fifth, the $t$-statistics for population represented the smallest of all significant variables, showing weak influence of population on production. This small effect of population is consistent with above-mentioned results of the restriction of internal migration.

\section{Conclusion and Future Development}

The primary purpose of this paper is to establish an archetype for issues of regional inequalities. From the results provided by the $\beta$ and $\sigma$ convergence model, the following were obtained.

First, it is reasonable to suppose that regional inequalities in per capita production have been diverging in Vietnam, or at least remained unchanged. This is due to rapid manufacturing growth and integration, pointing to the need to invest public capital and to develop the economy in the lessdeveloped northern mountainous areas.

Second, population growth was unable to offset regional inequalities in total per capita production in developed areas. This is probably because little internal migration occurred alongside increased production, due to restrictive policies concerning domestic migration. Controlled population movement is likely the cause of greater divergence in per capita production.

Third, public capital stock and foreign direct investment have recently boosted total production, particularly manufacturing production and retail trades. In agriculture, production is being increased by expanding cultivated areas. From this point, increased land productivity and investment policies will dictate the pace of continued development in Vietnam.

Finally, I would like to mention some further issues in relation to this study. First, data collection would, under ideal circumstances, be made more precise for each province. This would permit more concrete analysis of the implications of regional policies. Second, the method used in this paper may be profitably extended to other countries. Third, we should continue to investigate other models of regional inequalities.

\section{References}

[1] Aramaki, Kenji, "Asian monetary crisis and IMF-Bright and dark side of Globalization," nihonhyoronsha, 1999, pp. 96.

[2] Barro, Robert (J) and Xavier Sala-i-Martin, "Convergence across States and Regions," Brookings Papers on Economic Activity, 1991, pp. 107-182.

[ 3 ] Ben-David, Dan "Convergence Clubs and Diverging Economies," Working paper, No. 40-95, The Foerder Institute for Economic Research, November 1995, pp. 1-12.

[4] Campbell, John (Y) and Pierre Perron, "Pitfalls and Opportunities: What Macroeconomists Should Know about Unit Roots," NBER Macroeconomic Annual, pp. 141-201.

[5] Hayami, Yujiro, "Income distribution and environmental problem," development economics, Sobun-sha, 1995, pp. 189-191.

[6] Hirschman, Albert (O), "The Strategy of Economic Development," 1958, trans. Shiro Asada, Gennsho-do, 1969, pp. 52-127.

[7] Kawabata, Koji, "Convergence of Regional Economies in China-Statistical Tests by Crosssection and Time-series," Ajia keizai, Institute of Developing Economies, Vol. 41, No. 6, pp. 2033.

[8 ] Koopmans, Tjalling (C), "On the Concept of Optimal Economic Growth," in The Econometric Approach to Development Planning, Amsterdam, North Holland, 1965.

[ 9 ] Kunimitsu, Yoji, "Econometric Model Analysis about Economic Growth in Vietnam-the influence of reformation policy and overseas assistance fund-," Studies in Regional Science, Vol. 26, 1996, 
pp. 61-74.

[10] Kunimitsu, Yoji, "Econometrical Analysis of Production Structure in Vietnam-in terms of total factor productivity and input factor movement-," Studies in Regional Science, Vol. 27, 1997, pp. 51-64.

[11] Kuznets, Simon, "Economic Growth and Income Inequality," American Economic Review, Vol. 14, 1965, pp. 1-28.

[12] Levin, Andrew and Chien-Fu Lin, "Unit Root Tests in Panel Data : New Results," University of California San Diego Discussion Paper, 1993, pp. 93-156.

[13] Paukert, Felix, "Income Distribution at Different Levels of Development: A Survey of Evidence," International Labor Review, Vol. 108, no. 2/3, 1973, pp. 97-125.

[14] Quah, Danny, "Exploiting Cross-Section Variation for Unit Root Inference in Dynamic Data," Economic Letters, Vol. 44, 1994, pp. 9-19.

[15] Williamson, Jeffrey (G), "Regional Inequality and the Process of National Development: A Description of Patterns," Economic Development and Cultural Change, Vol. 13, 1965, pp. 3-45. 